\title{
Temas tributarios y de NIIF que debemos tomar en cuenta para proyectar el año 2011
}

Jorge Zapata Lara*

\begin{abstract}
Resumen
El presente compendio de normas financieras nos da las pautas para el establecimiento de estrategias para guiar el eficiente desempeño de las organizaciones frente a las diferentes reformas tributarias y la dinámica que impone el proceso de implementación de las Normas Internacionales de Información Financiera en las que está inmerso el Ecuador, además permite realizar un análisis de los principales eventos relacionados en este ámbito con el objeto de facilitar la proyección de los diferentes procesos contables y financieros para el año 2011.
\end{abstract}

\section{Palabras clave}

NIIF, estrategias financieras, normas internacionales de información financiera Ecuador.

\begin{abstract}
This compendium of financial standards provides guidelines for establishing strategies to guide the efficient performance of organizations, the different legal tax reforms and the dynamics imposed by the process of implementing International Financial Reporting Standards in which is immersed Ecuador, allows an analysis of the main events in this area in order to facilitate the screening of the different accounting and financial processes for the year 2011.
\end{abstract}

\section{Key words}

IFRS, financial strategies, international financial reporting standards Ecuador.

Forma sugerida de citar: Zapata Lara, Jorge. 2011. Temas tributarios y de NIFF que debemos tomar en cuenta para proyectar el año 2011. Retos 1. Enero/Junio. Pp. 19-23.

* Docente de la Universidad Politécnica Salesiana. Carrera de Contabilidad y Auditoría-Sede Quito. jzapata@ups.edu.ec

Retos I(I): 20II.

(c) 201 I, Universidad Politécnica Salesiana del Ecuador 


\section{Retos}

Temas tributarios y de NIIF que debemos tomar en cuenta para proyectar el año 2011

El Ecuador se encuentra inmerso en un proceso de implementación de las Normas Internacionales de Información Financiera (NIIF), en el 2010 se dieron una serie de reformas en el sector tributario ya que la administración tributaria busca ejercer mayor pre- sión para generar un mayor nivel de recaudaciones.

Conviene entonces realizar un análisis de los principales eventos relacionados con estos temas con el objeto de facilitar la proyección de estrategias para el año 2011. 


\section{EVENTOS TRIBUTARIOS OCURRIDOS EN 2010, QUE GENERAN OBLIGACIONES PARA EL 2011}

Junio de 2010

NAC-DGERCGC10-00147

A partir de la publicación de esta resolución del SR:

Están sujetos a la retención del $8 \%$ de honorarios y demás pagos realizados a personas naturales nacionales o extranieras residentes en el país por más de seis meses, que presten servicios de docencia.

Están sujetos a la retención del 10\% los pagos o acreditaciones en cuenta por honorarios, comisiones y demás pagos realizados a personas naturales profesionales nacionales o extranjeras residentes en el país por más de seis meses, que presten servicios en los que prevalezca el intelecto sobre la mano de obra, siempre y cuando, los mismos estén relacionados con su título profesional; si los servicios que presta no están relacionados con dicho título profesional, la retención será del 8\%.

RO. 209, 08-06-2010

Nuevo esquema para el cálculo y pago del anticipo de impuesto a la renta

Para calcular el anticipo de impuesto a la renta deben tomarse en cuenta los siguientes aspectos:

El anticipo se calcula y se paga después del segundo año completo de operación efectiva.

Corresponde a la sumatoria de los siguientes rubros:

- $\quad$ El $0,2 \%$ del patrimonio total.

* El 0,2\% del total de costos y gastos deducibles.

- $\quad$ El $0,4 \%$ del activo total.

* $\mathrm{El} 0,4 \%$ del total de ingresos gravables.

Si usted es una persona natural, no debe incluir sus activos de uso personal, en el total de activos para el cálculo del anticipo.

El valor de las retenciones que le efectuaron se resta del anticipo, pero no disminuyen el mismo. La resta se la hace únicamente con la finalidad de establecer los valores a pagar en cada cuota. Las cuentas por cobrar a clientes no deben ser incluidas en el total de activos.

Si considera que ha calculado mal el anticipo, es mejor proceder a realizar la corrección correspondiente a efecto de evitar sanciones.

RO. 209, 08-06-2010 Reformas al reglamento a la lort

Las reformas más importantes, incluyen los siguientes temas:

La retención en la fuente en el pago de dividendos, se establece en 10\% de valor pagado, cuando dicho dividendo se pague a sociedades domiciliadas en paraísos fiscales o de menor imposición que en el Ecuador.

Se crea la definición de empresas: inexistente, fantasmas o supuestas:

Reforma en los requisitos para deducción por pagos al exterior.

Se definen límites individuales para los gastos personales que son deducibles para el cálculo de impuesto a la renta desde 2011, as:

- Vivienda $\$ 2.895,75(2)$

- Educación \$2.895,75

- Alimentación \$2.895,75

- Vestimenta $\$ 2.895,75$

- Salud $\$ 11.583,00(3)$

(1) = Corresponde al $32,50 \%$ de la fracción básica de la tabla de impuesto a la renta - personas naturales.

(2) = Corresponde al $130 \%$ de la fracción básica de la tabla de impuesto a la renta - personas naturales.

El valor deducible total se mantiene en $\$ 11.583,00$ siempre que no sea mayor al $50 \%$ del ingreso gravado.

Estados financieros a ser utilizados en el análisis de crédito en las instituciones financieras serán los mismos estados financieros que sirvieron para fines tributarios.

Quienes promuevan un espectáculo público, deberán declarar y pagar, como anticipo adicional del impuesto a la renta, un 3\% sobre los ingresos generados por el espectáculo.

Ventajas para turismo receptivo, discapacitados y tercera edad.

Las personas de la tercera edad tienen derecho a que el IVA que paguen en la adquisición de bienes y servicios de su uso y consumo personal les sea reintegrado a través de la emisión de la respectiva nota de crédito, cheque u otro medio de pago, sin intereses, en un tiempo no mayor a noventa (90) días de presentada su solicitud, con una única base imponible máxima de consumo de hasta cinco remuneraciones básicas.

Retos I(1): 2011 .

Rerll, 2011. 


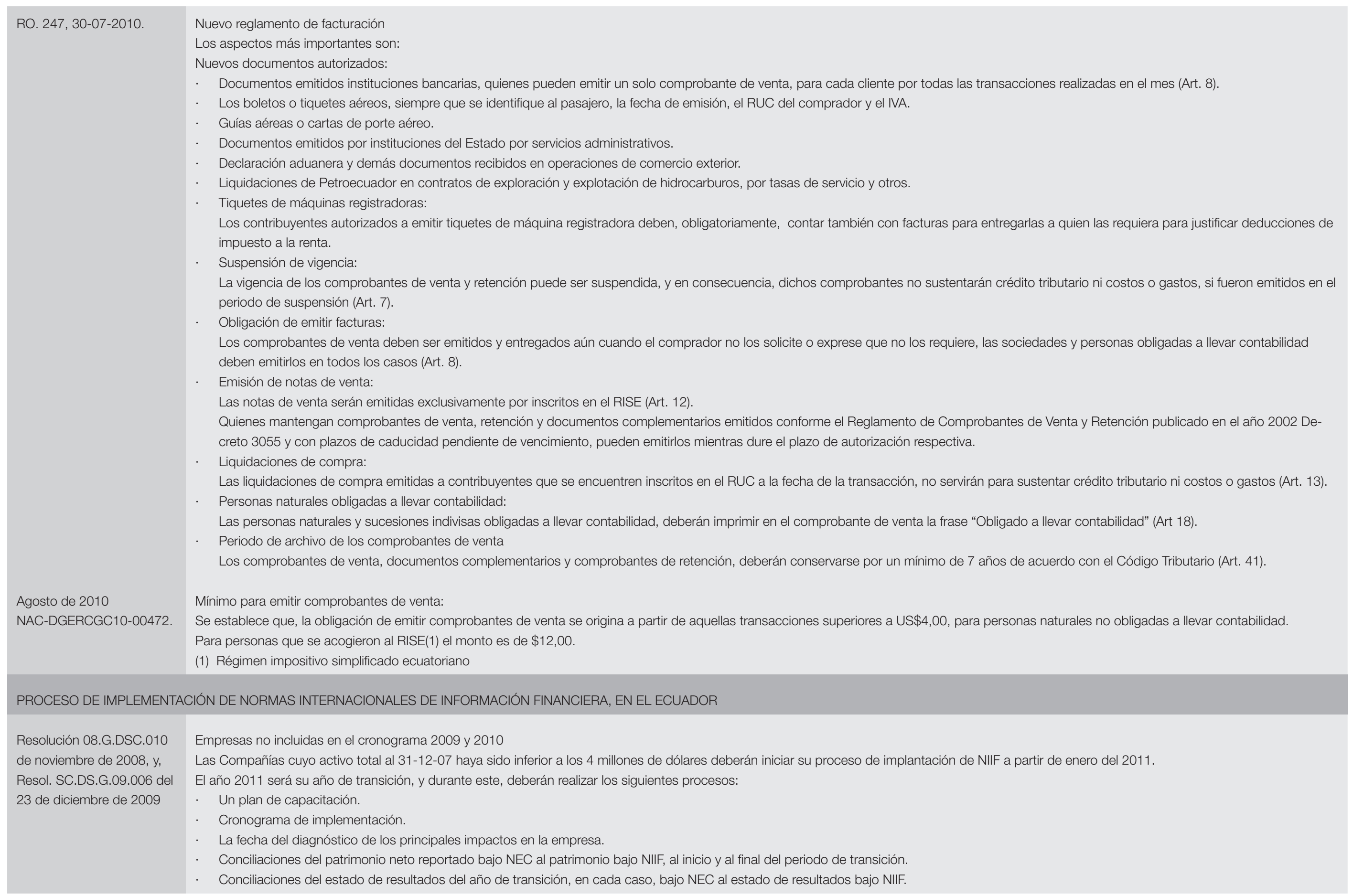


Explicar cualquier ajuste material si lo hubiere al estado de flujos efectivo del periodo de transición, en cada caso, previamente presentado bajo NEC.

Esta información deberá ser aprobada por la junta general de accionistas.

Los ajustes efectuados al término del periodo de transición, al 31 de diciembre de 2011, deberán contabilizarse el 1 de enero de 2012.

El año 2012 será su año de implementación, las premisas importantes a tomar en cuentas durante la implementación son:

Las transacciones de la compañía se contabilizarán bajo los principios contables vigentes, independiente del tema tributario.

Si la legislación tributaria describe una forma diferente de registrar las transacciones, se considerará como un ajuste en la conciliación tributaria.

Para efectos de presentar los estados financieros trimestrales se puede optar por las siguientes opciones:

Opción 1: Presentación de estados financieros trimestrales y anuales del 2012 (incluidas notas explicativas) comparativos con 2011, aplicando íntegramente las NIIF.

Opción 2: EEFF bajo NEC los primeros tres trimestres de 2012, comparativos con 2011, y, EEFF anuales de 2012 (incluidas notas explicativas), aplicando íntegramente las NIIF.

Envío 22 de febrero de 2011 - aprobación 29 de marzo de 2011

www.jezl-auditores.com.

Retos I(I): 2011.

( 2011 . Universidad Politécnica Salesiana del Ecuador 